OPEN ACCESS

Edited by:

Arjan Te Pas,

Leiden University, Netherlands

Reviewed by:

Paolo Roma,

Sapienza University of Rome, Italy

Martin Chalumeau,

Université Paris Descartes, France

*Correspondence:

Adamos Hadjipanayis adamos@paidiatros.com

Specialty section:

This article was submitted to

Children and Health

a section of the journal

Frontiers in Pediatrics

Received: 12 March 2021 Accepted: 16 April 2021

Published: 11 May 2021

Citation:

Dembiński Ł. Huss G,

Radziewicz-Winnicki I, Grossman Z,

Mazur A, del Torso S, Barak S,

Carrasco Sanz A and Hadjipanayis A (2021) EAP and ECPCP Statement

Risks for Children's Health During the COVID-19 Pandemic and a Call for Maintenance of Essential Pediatric

Services. Front. Pediatr. 9:679803.

doi: 10.3389/fped.2021.679803

\section{EAP and ECPCP Statement Risks for Children's Health During the COVID-19 Pandemic and a Call for Maintenance of Essential Pediatric Services}

\author{
Łukasz Dembiński ${ }^{1,2}$, Gottfried Huss ${ }^{3,4}$, Igor Radziewicz-Winnicki ${ }^{5}$, Zachi Grossman ${ }^{1,6,7}$, \\ Artur Mazur ${ }^{1,5}$, Stefano del Torso ${ }^{1,8}$, Shimon Barak ${ }^{3,9}$, Angel Carrasco Sanz ${ }^{3,10}$ and \\ Adamos Hadjipanayis ${ }^{1,11,12 *}$ \\ ${ }^{1}$ The European Academy of Paediatrics, EAP, Brussels, Belgium, ${ }^{2}$ Department of Pediatric Gastroenterology and Nutrition, \\ Medical University of Warsaw, Warsaw, Poland, ${ }^{3}$ The European Confederation of Primary Care Paediatricians (ECPCP), \\ Lyon, France, ${ }^{4}$ Kinder-Permanence Spital Zollikerberg, Zollikerberg, Switzerland, ${ }^{5}$ Medical Faculty, University of Rzeszow, \\ Rzeszów, Poland, ${ }^{6}$ Adelson School of Medicine, Ariel University, Ariel, Israel, ${ }^{7}$ Maccabi Health Services, Tel Aviv, Israel, \\ ${ }^{8}$ ChildCare WorldWide, Padova, Italy, ${ }^{9}$ Dana-Dwek Children's Hospital, Tel Aviv Sourasky Medical Center, Tel Aviv, Israel, \\ ${ }^{10}$ Madrid Health Service, Servicio Madrileño de Salud, Madrid, Spain, ${ }^{11}$ School of Medicine, European University Cyprus, \\ Nicosia, Cyprus, ${ }^{12}$ Paediatric Department, Larnaca General Hospital, Larnaca, Cyprus
}

The COVID-19 pandemic and global lockdown have had drastic socioeconomic and psychological effects on countries and people, respectively. There has been limited access to health care and education. These negative consequences have had a significant impact on the well-being of children and adolescents. Therefore, the EAP and the ECPCP are requesting state, health, and education authorities as well as European pediatric societies and the healthcare professionals that special attention be given to this population and the problems they face as a result of the pandemic.

Keywords: adolescents, community pediatrics, lockdown, mental health, pediatric primary care, SARS-CoV-2, school, vaccines

\section{INTRODUCTION}

The COVID-19 pandemic has caused unprecedented changes in people's way of life and social relationships. Global public health measures, including a worldwide lockdown, have affected socioeconomics, health care, education, and public mental health (1-5). This has had a major impact on children and adolescents, affecting their physical, intellectual, and emotional development (6). Approximately $90 \%$ of children and adolescents, estimated as 1.5 billion young people worldwide, have been obliged to stay at home, significantly influencing their health and social functioning (7).

To highlight this issue, provide guidance, and offer strategies for the prevention or minimization of the detrimental effects of the pandemic and associated lockdown on young people, the European Academy of Paediatrics (EAP) and the European Confederation of Primary Care Paediatricians (ECPCP) present this position paper and recommendations directed to state, health authorities, European pediatric societies, and the European healthcare professionals involved in the care of the pediatric population. This statement does not focus on the care of children and adolescents with COVID-19 disease. 


\section{ESSENTIAL PEDIATRIC CARE}

The course of SARS-CoV-2 infection is rarely severe in children and adolescents (8-10). However, the long-term consequences of the limited access to essential medical care resulting from the pandemic restrictions should not be underestimated (1116). Pediatric consultations in primary care and in hospitals dropped dramatically due to the fearfulness of parents and restrictions in the health care delivery (17). Primary medical care has largely been limited to remote consultations. This has resulted in delays to child presentations at emergency departments and specialist centers (18). The diagnosis of conditions such as diabetes mellitus, dehydration, appendicitis, sepsis, and neoplastic diseases have been significantly delayed in many instances (19-22). Limited access to health care has a particularly negative impact on newborns and young children $(23,24)$.

\section{WELL-CHILD CARE AND VACCINATION}

The lockdown has also affected the availability of well-child care and the administration of childhood inoculations for vaccinepreventable diseases. Many children, especially those from lower-income households, have not received scheduled routine vaccinations and the overall immunization rate has dropped significantly (25-27). This puts children at risk for the resurgence of life-threatening vaccine-preventable diseases.

\section{MENTAL HEALTH AND DEVELOPMENT IN THE COMMUNITY}

Limited access to mental health services for children and adolescents has resulted in the intensification of preexisting problems and an increase in the prevalence of depression and anxiety disorders (28-30).

The new situation has led to weakened communication, deprivation of personal peer relations, lack of physical activity, and reduced sensory stimulation. The consequences of this can include psychological deterioration, anxiety, frustration, stress disorder, adjustment disorders, grief, loss of appetite, and sleep problems $(5,31,32)$. The adverse effects of social isolation are particularly great among adolescents as social relationships are extremely important during this stage of development $(33,34)$. These psychological and emotional difficulties are likely to be externalized as negative behavior. Many parents and caregivers are also experiencing greater stress because of the lockdown and home schooling and increased time with their children has caused many to feel uncertain of their parental abilities, which is especially apparent in the group characterized by the following factors: motherhood, being single, having younger children, having a special needs child, and having many children (35). These factors combined are liable to lead to intra-family conflicts and, in some cases, family violence (36-38). The data show an increase in the number of children exposed to violence and witnessing domestic violence during the pandemic. Whereas, limited school activities and reduced direct contact with primary healthcare may cause a decrease in child abuse victims' identification (39-41).

Social distancing and limited interpersonal contact can lead to development delays, impaired social skills, anxiety, and depressive symptoms (42). The lengthy, ongoing COVID-19 lockdown has caused a significant rise in suicidal ideation and behaviors among school children. Suicide and self-harm rates in minors have risen in both the general population and those with preexisting mental health disorders (43-45).

The transference of social activity exclusively to the Internet can result in digital technology overuse, abandonment of other activities, exposure to inappropriate content, and cyberbullying $(46,47)$.

\section{SAFE REOPENING OF SCHOOLS DURING COVID-19 PANDEMIC}

The prolonged school closures are likely to have detrimental effects on learning outcomes (48-50). In younger children, the presence of a teacher during educational activities is much more important. Children whose schooling has just begun require more time and attention from educators than older children (51).

The lockdown exacerbates socioeconomic inequalities. In the context of education, this can mean that children from poorer families are likely to have inadequate access to appropriate IT tools, insufficient intellectual support from caregivers, and fewer educational opportunities beyond school. As they do not receive meals at school during the lockdown, these children are also at increased risk of malnutrition $(4,52)$. Moreover, in children with special needs, such as autism spectrum disorders or learning disabilities, the lockdown-related transition to elearning has been found to result in therapy discontinuation in many instances (32).

For teachers, the pandemic has been a challenge related to the crisis of competence. Educators have had to develop and improve objective methods of assessing learning progress. Remote education has also weakened teacher-student relationships $(50,53)$.

\section{RECOMMENDATIONS ON ESSENTIAL PEDIATRIC SERVICES}

The EAP and the ECPCP strongly believe that action is necessary to reduce the negative effects of the pandemic on young people. The following measures are advised:

- For state, health, and education authorities

- Establish a framework on how to mitigate the impact of COVID-19 on children and adolescents needing essential services in a variety of healthcare settings.

- Consider strategies to reduce preventable illness during the COVID-19 pandemic in young people with non-COVID-19 diseases and injuries.

- Guarantee the staffing, adequate drug, and material supply, especially for personal protective equipment for essential pediatric services. 
- Implement secure and flexible reopening and maintenance of kindergartens and schools based on the rights of children and adolescents.

- For European pediatric societies:

- Keep members updated in the area of risks for child and adolescent health during the COVID-19 pandemic.

- Encourage members to make all possible efforts to maintain curative and preventive high-quality services for children and adolescents.

- Initiate and coordinate European-wide surveys regarding the temporary impact of the COVID-19 pandemic on pediatric health services.

- Analyze the experiences with telemedicine in the area of pediatric care, screening, follow-up, and drug prescribing.

- Support the EAP campaign "Vaccinate your child," to restore routine immunization of children (54).

- For the providers in the primary, secondary, and specialized pediatric care

- Increase vigilance and diligence about the risks of nonpersonal appointments when conducting remote health assessments of children and adolescents.

- Encourage face-to-face visits when presenting symptoms require them to rule out life-threatening diseases. Provide postnatal care in person wherever possible.

- Ensure hygienic measures and personal protection for all staff and patients. Make appropriate adjustments and appointments to avoid crowding in outpatient services. Limit the quantity of accompanying persons.

- Communicate personally and in public with caregivers to reassure the trust in essential health services and the unlikely danger of COVID-19 infection in the health care system. Clarify any public misinformation.

\section{REFERENCES}

1. Bonaccorsi G, Pierri F, Cinelli M, Flori A, Galeazzi A, Porcelli F, et al. Economic and social consequences of human mobility restrictions under COVID-19. Proc Natl Acad Sci USA. (2020) 117:15530-5. doi: 10.1073/pnas.2007658117

2. L'Angiocola PD, Monti M. COVID-19: the critical balance between appropriate governmental restrictions and expected economic, psychological and social consequences in Italy. Are we going in the right direction? Acta Biomed. (2020) 91:35-8. doi: 10.23750/abm.v91i2.9575

3. Kaye AD, Okeagu CN, Pham AD, Silva RA, Hurley JJ, Arron BL, et al. Economic impact of COVID-19 pandemic on healthcare facilities and systems: international perspectives. Best Pract Res Clin Anaesthesiol. (2020). doi: 10.1016/j.bpa.2020.11.009. [Epub ahead of print].

4. UNESCO. Adverse Consequences of School Closures. (2020). Available online at: https://en.unesco.org/covid19/educationresponse/consequences (accessed March 01, 2021).

5. Morgül E, Kallitsoglou A, Essau CA. Psychological effects of the COVID-19 lockdown on children and families in the UK. Revista de Psicología Clínica con Niños y Adolescentes. (2020) 7:7. doi: 10.21134/rpcna.2020.mon.2049

6. Singh S, Roy D, Sinha K, Parveen S, Sharma G, Joshi G. Impact of COVID-19 and lockdown on mental health of children and adolescents: a narrative review with recommendations. Psychiatry Res. (2020) 293:113429. doi: 10.1016/j.psychres.2020.113429
- Reinforce the capacity of parents and adolescents for selfmanagement and timely presentation in case of alarming signs and symptoms.

- Make every effort to maintain essential pediatric health services by facilitating open access to curative services for the acute and the chronic ill children and adolescents.

- Maintain preventive health services as well as child checks and vaccinations. Use recall and other motivational reminder systems to catch-up with missed visits.

- Increase surveillance and screening for emotional, social, and behavioral disorders and provide age-appropriate guidance at any given opportunity.

- Engage to maintain mental health services and social services in the community, with special focus on lowerincome households.

- Encourage adolescents to discuss non-pharmacological COVID-19 interventions such as social distancing, hygiene, and the use of face coverings. This will enable them to identify and minimize behavioral infection risks, which may be detrimental even in areas with high vaccination rates.

\section{DATA AVAILABILITY STATEMENT}

The original contributions presented in the study are included in the article/supplementary material, further inquiries can be directed to the corresponding author/s.

\section{AUTHOR CONTRIBUTIONS}

$€ D, A M$, and $A H$ : study design. $€ D, I R-W$, and $G H$ : data collection. $€ D, I R-W, G H, Z G, A M, S T, S B, A C$, and AH: data analysis and interpretation, manuscript preparation, and critical revision. All authors read and approved the final manuscript.

7. UNESCO. COVID-19 Educational Disruption and Response. (2020). Available online at: https://en.unesco.org/news/covid-19-educational-disruption-andresponse (accessed March 01, 2021).

8. de Souza TH, Nadal JA, Nogueira RJN, Pereira RM, Brandao MB. Clinical manifestations of children with COVID-19: a systematic review. Pediatr Pulmonol. (2020) 55:1892-9. doi: 10.1002/ppul.24885

9. Götzinger F, Santiago-García B, Noguera-Julián A, Lanaspa M, Lancella L, Calò Carducci FI, et al. COVID-19 in children and adolescents in Europe: a multinational, multicentre cohort study. Lancet Child Adolesc Health. (2020) 4:653-61. doi: 10.1016/S2352-4642(20)30177-2

10. Klein JD, Koletzko B, El-Shabrawi MH, Hadjipanayis A, Thacker N, Bhutta Z. Promoting and supporting children's health and healthcare during COVID19 - international paediatric association position statement. Arch Dis Child. (2020) 105:620-4. doi: 10.1136/archdischild-2020-319370

11. Hefferon C, Taylor C, Bennett D, Falconer C, Campbell M, Williams JG, et al. Priorities for the child public health response to the COVID-19 pandemic recovery in England. Arch Dis Child. (2020). doi: 10.1136/archdischild-2020-320214. [Epub ahead of print].

12. Clay LA, Rogus S. Primary and secondary health impacts of COVID-19 among minority individuals in New York State. Int J Environ Res Public Health. (2021) 18:683. doi: 10.3390/ijerph18 020683

13. Doná D, Torres Canizales J, Benetti E, Cananzi M, De Corti F, Calore E, et al. Pediatric transplantation in Europe during the COVID-19 
pandemic: early impact on activity and healthcare. Clin Transplant. (2020) 34:e14063. doi: $10.1111 /$ ctr. 14063

14. Zemrani B, Gehri M, Masserey E, Knob C, Pellaton R. A hidden side of the COVID-19 pandemic in children: the double burden of undernutrition and overnutrition. Int $J$ Equity Health. (2021) 20:44. doi: 10.1186/s12939-021-01390-w

15. Walker DM, Tolentino VR. COVID-19: the impact on pediatric emergency care. Pediatr Emerg Med Pract. (2020) 17(Suppl. 6-1):1-27.

16. Dan B. Long-term impact of COVID-19 on disabled children. Dev Med Child Neurol. (2020) 62:1004. doi: 10.1111/dmcn.14603

17. Gottfried Huss CM. ECPCP. How Did the COVID-19 Pandemic Change Paediatric Primary Care? Results of a European Primary Care Survey. (2020) Available online at: https://www.ecpcp.eu/fileadmin/pdf_doc_ppt/Data results_of_the_PCP_survey_for_Websites_ECPCP_and_EPA-_UNEPSA. pdf (accessed March 01, 2021).

18. Lazzerini M, Barbi E, Apicella A, Marchetti F, Cardinale F, Trobia G. Delayed access or provision of care in Italy resulting from fear of COVID-19. Lancet Child Adolesc Health. (2020) 4:e10-e1. doi: 10.1016/S2352-4642(20)30108-5

19. Lynn RM, Avis JL, Lenton S, Amin-Chowdhury Z, Ladhani SN. Delayed access to care and late presentations in children during the COVID-19 pandemic: a snapshot survey of 4075 paediatricians in the UK and Ireland. Arch Dis Child. (2021) 106:e8. doi: 10.1136/archdischild-2020-319848

20. Dzygało K, Nowaczyk J, Szwilling A, Kowalska A. Increased frequency of severe diabetic ketoacidosis at type 1 diabetes onset among children during COVID-19 pandemic lockdown: an observational cohort study. Pediatr Endocrinol Diabetes Metab. (2020) 26:167-75. doi: 10.5114/pedm.2020.101003

21. Yeshayahu Y. Delayed presentation of children to healthcare facilities due to COVID-19 lockdown, leading to severe complications. Rambam Maimonides Med J. (2021). doi: 10.5041/RMMJ.10431. [Epub ahead of print].

22. Raucci U, Musolino AM, Di Lallo D, Piga S, Barbieri MA, Pisani $\mathrm{M}$, et al. Impact of the COVID-19 pandemic on the Emergency Department of a tertiary children's hospital. Ital J Pediatr. (2021) 47:21. doi: 10.1186/s13052-021-00976-y

23. Vazquez-Vazquez A, Dib S, Rougeaux E, Wells JC, Fewtrell MS. The impact of the Covid-19 lockdown on the experiences and feeding practices of new mothers in the UK: Preliminary data from the COVID-19 New Mum Study. Appetite. (2021) 156:104985. doi: 10.1016/j.appet.2020.104985

24. Brown A, Shenker N. Experiences of breastfeeding during COVID-19: lessons for future practical and emotional support. Matern Child Nutr. (2021) 17:e13088. doi: $10.1111 / \mathrm{mcn} .13088$

25. McDonald HI, Tessier E, White JM, Woodruff M, Knowles C, Bates C, et al. Early impact of the coronavirus disease (COVID-19) pandemic and physical distancing measures on routine childhood vaccinations in England, January to April 2020. Euro Surveill. (2020) 25:2000848. doi: 10.2807/1560-7917.ES.2020.25.19.2000848

26. Bell S, Clarke R, Paterson P, Mounier-Jack S. Parents' and guardians' views and experiences of accessing routine childhood vaccinations during the coronavirus (COVID-19) pandemic: a mixed methods study in England. PLoS ONE. (2020) 15:e0244049. doi: 10.1371/journal.pone.0244049

27. Bechini A, Garamella G, Giammarco B, Zanella B, Flori V, Bonanni P, et al. Paediatric activities and adherence to vaccinations during the COVID-19 epidemic period in Tuscany, Italy: a survey of paediatricians. J Prev Med Hyg. (2020) 61:E125-e9. doi: 10.15167/2421-4248/jpmh2020.61.2.1626

28. Golberstein E, Wen H, Miller BF. Coronavirus disease 2019 (COVID-19) and Mental Health for Children and Adolescents. JAMA Pediatr. (2020). 174:819-20. doi: 10.1001/jamapediatrics.2020.1456

29. Ravens-Sieberer U, Kaman A, Erhart M, Devine J, Schlack R, Otto C. Impact of the COVID-19 pandemic on quality of life and mental health in children and adolescents in Germany. Eur Child Adolesc Psychiatry. (2021). doi: 10.1007/s00787-021-01726-5. [Epub ahead of print].

30. Nearchou F, Flinn C, Niland R, Subramaniam SS, Hennessy E. Exploring the impact of COVID-19 on mental health outcomes in children and adolescents: a systematic review. Int J Environ Res Public Health. (2020) 17:8479. doi: 10.3390/ijerph17228479

31. Liu JJ, Bao Y, Huang X, Shi J, Lu L. Mental health considerations for children quarantined because of COVID-19. Lancet Child Adolesc Health. (2020) 4:347-9. doi: 10.1016/S2352-4642(20)30096-1
32. Lee J. Mental health effects of school closures during COVID-19. Lancet Child Adolesc Health. (2020) 4:421. doi: 10.1016/S2352-4642(20)30109-7

33. Orben A, Tomova L, Blakemore S-J. The effects of social deprivation on adolescent development and mental health. Lancet Child Adolesc Health. (2020) 4:634-40. doi: 10.1016/S2352-4642(20)30186-3

34. Högnäs RS, Almquist YB, Modin B. Adolescent social isolation and premature mortality in a Swedish birth cohort. $J$ Population Res. (2020) 37:1-23. doi: 10.1007/s12546-019-09237-6

35. Marchetti D, Fontanesi L, Mazza C, Di Giandomenico S, Roma P, Verrocchio MC. Parenting-related exhaustion during the Italian COVID-19 lockdown. J Pediatr Psychol. (2020) 45:1114-23. doi: 10.1093/jpepsy/jsaa093

36. Achterberg M, Dobbelaar S, Boer OD, Crone EA. Perceived stress as mediator for longitudinal effects of the COVID-19 lockdown on wellbeing of parents and children. Sci Rep. (2021) 11:2971. doi: 10.1038/s41598-021-81720-8

37. Xue A, Oros V, Marca-Ghaemmaghami P, Scholkmann F, Righini-Grunder F, Natalucci G, et al. New parents experienced lower parenting selfefficacy during the COVID-19 pandemic lockdown. Children. (2021) 8:79. doi: $10.3390 /$ children 8020079

38. Humphreys KL, Myint MT, Zeanah CH. Increased risk for family violence during the COVID-19 pandemic. Pediatrics. (2020) 146:e20200982. doi: 10.1542/peds.2020-0982

39. Fabbri C, Bhatia A, Petzold M, Jugder M, Guedes A, Cappa C, et al. Modelling the effect of the COVID-19 pandemic on violent discipline against children. Child Abuse Negl. (2020). doi: 10.1016/j.chiabu.2020.104897. [Epub ahead of print].

40. Garstang J, Debelle G, Anand I, Armstrong J, Botcher E, Chaplin H, et al. Effect of COVID-19 lockdown on child protection medical assessments: a retrospective observational study in Birmingham, UK. BMJ Open. (2020) 10:e042867. doi: 10.1136/bmjopen-2020-042867

41. Calvano C, Engelke L, Di Bella J, Kindermann J, Renneberg B, Winter SM. Families in the COVID-19 pandemic: parental stress, parent mental health and the occurrence of adverse childhood experiences-results of a representative survey in Germany. Eur Child Adolesc Psychiatry. (2021) 113. doi: 10.1007/s00787-021-01739-0. [Epub ahead of print].

42. Oosterhoff B, Palmer CA, Wilson J, Shook N. adolescents' motivations to engage in social distancing during the COVID-19 pandemic: associations with mental and social health. J Adolesc Health. (2020) 67:179-85. doi: 10.1016/j.jadohealth.2020.05.004

43. Mourouvaye M, Bottemanne H, Bonny G, Fourcade L, Angoulvant F, Cohen JF, et al. Association between suicide behaviours in children and adolescents and the COVID-19 lockdown in Paris, France: a retrospective observational study. Arch Dis Child. (2020). doi: 10.1136/archdischild-2020-320628. [Epub ahead of print].

44. Carr MJ, Steeg S, Webb RT, Kapur N, Chew-Graham CA, Abel KM, et al. Effects of the COVID-19 pandemic on primary care-recorded mental illness and self-harm episodes in the UK: a population-based cohort study. Lancet Public Health. (2021) 6:e124-35. doi: 10.1016/S2468-2667(20)30288-7

45. Longobardi C, Morese R, Fabris MA. COVID-19 emergency: social distancing and social exclusion as risks for suicide ideation and attempts in adolescents. Front Psychol. (2020) 11:551113. doi: 10.3389/fpsyg.2020.551113

46. Ferrara P, Franceschini G, Corsello G, Mestrovic J, Giardino I, Vural M, et al. The dark side of the web-a risk for children and adolescents challenged by isolation during the novel coronavirus 2019. Pandemic. J Pediatr. (2021) 228:324-5.e2. doi: 10.1016/j.jpeds.2020.10.008

47. Montag C, Elhai JD. Discussing digital technology overuse in children and adolescents during the COVID-19 pandemic and beyond: on the importance of considering affective neuroscience theory. Addict Behav Rep. (2020) 12:100313. doi: 10.1016/j.abrep.2020.100313

48. Dong C, Cao S, Li H. Young children's online learning during COVID-19 pandemic: Chinese parents' beliefs and attitudes. Child Youth Serv Rev. (2020) 118:105440. doi: 10.1016/j.childyouth.2020.10 5440

49. Di Pietro G BF, Costa P, Karpiński Z, Mazza, J. Technical report by the Joint Research Centre of the European Commission's science and knowledge service. The Likely Impact of COVID-19 on Education: Reflections Based on the Existing Literature and Recent International Datasets. (2020). Available online at: https://publications.jrc.ec.europa.eu/repository/ bitstream/JRC121071/jrc121071.pdf (accessed March 01, 2021). 
50. Huber SG, Helm C. COVID-19 and schooling: evaluation, assessment and accountability in times of crises-reacting quickly to explore key issues for policy, practice and research with the school barometer. Educ Assess Eval Accountability. (2020) 32:237-70. doi: 10.1007/s11092-020-09322-y

51. Bao X, Qu H, Zhang R, Hogan TP. Modeling reading ability gain in kindergarten children during COVID-19 school closures. Int $J$ Environ Res Public Health. (2020) 17:6371. doi: 10.3390/ijerph17 176371

52. Mayurasakorn K, Pinsawas B, Mongkolsucharitkul P, Sranacharoenpong K, Damapong SN. School closure, COVID-19 and lunch programme: unprecedented undernutrition crisis in low-middle income countries. $J$ Paediatr Child Health. (2020) 56:1013-7. doi: 10.1111/jpc.15018

53. Kim LE, Asbury K. 'Like a rug had been pulled from under you': The impact of COVID-19 on teachers in England during the first six weeks of the UK lockdown. Br J Educ Psychol. (2020). 90:1062-83. doi: 10.1111/bjep. 12381
54. EAP. "Vaccinate Your Child" Campaign. (2020). Available online at: https:// www.eapaediatrics.eu/eap4vaccinations-vaccinate-your-child/ (accessed March 01, 2021).

Conflict of Interest: The authors declare that the research was conducted in the absence of any commercial or financial relationships that could be construed as a potential conflict of interest.

Copyright ( 2021 Dembiński, Huss, Radziewicz-Winnicki, Grossman, Mazur, del Torso, Barak, Carrasco Sanz and Hadjipanayis. This is an open-access article distributed under the terms of the Creative Commons Attribution License (CC BY). The use, distribution or reproduction in other forums is permitted, provided the original author(s) and the copyright owner(s) are credited and that the original publication in this journal is cited, in accordance with accepted academic practice. No use, distribution or reproduction is permitted which does not comply with these terms. 